\title{
Conflicts in the functioning process urban communities: current state of research
}

\author{
A. I. Kolba ${ }^{1}$
}

${ }^{1}$ Kuban State University, 149 Stavropolskaya str., Krasnodar 350040, Russian Federation

DOI: $10.18255 / 2412-6519-2020-1-20-29$

Review
Full text in Russian

The article discusses the current state of research on the problems of urban communities in conflict. The research base was the corpus of domestic and foreign scientific publications, formed on the basis of a search in scientometric databases. Based on the review and analysis of scientific literature, the author identifies the main problems that are in the focus of attention of specialists: the essence of urban communities themselves, the parameters of their participation in urban politics, as well as their actual participation in conflict processes. In accordance with this, research areas and main issues that are at the center of scientific discussions are highlighted. These include the identification of the essential features of urban communities at the present stage of their development, taking into account network technologies of interaction; the formation of civil and political subjectivity of urban communities; ways to include urban communities in the system of political management of urban conflicts. The latter direction involves various formats of participation: from protest actions to the creation of collaborative planning institutions. In foreign studies at this stage, relatively more attention is paid to this issue than in Russian. The further necessity of studying the functioning of urban communities in conflict situations is substantiated.

Keywords: urban community; urban conflict; urban policy; collaborative planning; critical planning

\section{INFORMATION ABOUT THE AUTHORS}

$$
\begin{array}{l|l}
\text { Kolba Alexey I. } & \begin{array}{l}
\text { E-mail: alivka2000@mail.ru } \\
\text { Doctor of Sciences in Politics }
\end{array}
\end{array}
$$

Funding: RFBR, project 19-011-00571.

For citation: Kolba A. I. Conflicts in the functioning process urban communities: current state of research // Social'nye i gumanitarnye znanija. 2020. Vol. 6, No 1. P. 20-29. (in Russ.)

(C) Kolba A. I., 2020

This is an open access article under the CC BY-NC-ND license (http://creativecommons.org/licenses/by-nc-nd/4.0/) 


\title{
Конфликты в процессе функционирования городских сообществ: современное состояние исследований
}

\author{
А. И. Кольба 1
}

${ }^{1}$ Кубанский государственный университет, ул. Ставропольская, 149, Краснодар, 350040, Российская Федерация

DOI: $10.18255 / 2412-6519-2020-1-20-29$

УдК 352/354-1

Обзорная статья

Полный текст на русском языке

В статье рассматривается современное состояние исследований проблематики деятельности городских сообществ в условиях конфликта. Базой исследования стал корпус отечественных и зарубежных научных публикаций, сформированный на основе поиска в наукометрических базах. На основе проведённого обзора и анализа научной литературы автором выделяются основные проблемы, находящиеся в фокусе внимания специалистов: сущность самих городских сообществ, параметры их участия в городской политике, а также собственно участие в процессах конфликтования. В соответствии с этим выделены направления исследований и основные вопросы, находящиеся в центре научных дискуссий. К таковым относятся выявление сущностных признаков городских сообществ на современном этапе их развития с учётом сетевых технологий взаимодействия; формирование гражданской и политической субъектности городских сообществ; способы включения городских сообществ в систему политического управления городскими конфликтами. Последнее направление предполагает различные форматы участия: от протестных действий до создания институтов коллаборативного планирования. В зарубежных исследованиях на нынешнем этапе этой проблематике уделяется сравнительно больше внимания, нежели в российских. Обоснована дальнейшая необходимость исследования функционирования городских сообществ в условиях конфликтов.

Ключевые слова: городское сообщество; городской конфликт; городская политика; коллаборативное планирование; критическое планирование

ИНФОРМАЦИЯ ОБ АВТОРАХ

Кольба Алексей Иванович $\quad$ E-mail: alivka2000@mail.ru

Доктор политических наук, профессор кафедры

государственной политики и государственного управления

Финансирование: РФФИ, проект № 19-011-00571 «Конфликты в процессе функционирования городских сообществ крупных региональных центров России: концептуальные основания исследования и политические методы снижения деструктивного потенциала».

Для цитирования: Кольба А. И. Конфликты в процессе функционирования городских сообществ: современное состояние исследований // Социальные и гуманитарные знания. 2020. Том 6, № 1. С. 20 -29. 


\section{Введение}

Проблематика городской конфликтности всё чаще становится предметом научных исследований, выполненных как в русле какой-либо отдельной отрасли науки, так и междисциплинарных. В фокусе исследовательского внимания, как правило, оказывается такой коллективный субъект, как городские сообщества различного типа, которые наряду с местной властью и бизнесом составляют триаду основных акторов конфликтов. Рассматриваются стратегии их поведения в конфликте, взаимодействие с другими участниками, возможности оптимального сочетания интересов сообществ и девелоперов [1] и ряд других аспектов конфликтования. Однако в настоящее время сложившиеся представления об участии таких сообществ в конфликтах в недостаточной степени упорядочены и систематизированы, что препятствует их дальнейшему анализу. Необходимо выявить ключевые исследовательские проблемы и направления их исследования, а также возможные лакуны в научных представлениях об их объекте. Решению данной задачи посвящена настоящая публикация.

Предварительное изучение массива научных публикаций позволило выделить три группы исследовательских вопросов: сущность и определение самого понятия «городское сообщество»; процессы структуризации и функционирования таких сообществ в политическом пространстве города, в том числе в условиях конфликтов; собственно участие в конфликтах, поведенческие стратегии сообществ, их роль в управлении городскими конфликтами. Данные вопросы рассматриваются в ряде специализированных исследований, но зачастую затрагиваются в работах, где данная тематика является периферийной. В представленном обзоре мы будем учитывать обе группы научных публикаций.

\section{Городские сообщества: проблемы дефиниции и описания}

Определение городского сообщества, на первый взгляд, не представляет особой сложности. Как отмечал ещё Р. Парк, сообщество является зримым объектом, который можно показать и зафиксировать на карте [2]. Исходя из этого, достаточно просто не только редуцировать интересующее нас понятие, но и выделить сами сообщества на ограниченной и хорошо структурированной территории города. Однако «зримость» сообщества на современном этапе исследования данного феномена оборачивается весьма высокой мозаичностью подходов и дефиниций. Вопросы использования того или иного определения решаются в русле сложившихся исследовательских традиций, среди которых можно выделить антропологическую, экологическую, конструктивистскую, сетевую и др. Тем самым задаются определённые форматы описания сообществ, в том числе городских. По мнению В. Вагина, их можно объединить вокруг трёх пунктов: географическая зона; определённое качество отношений в группе (культура, ценности); устойчивое социальное взаимодействие [3].

Проблема взаимосвязи территориальных и социальных границ городских сообществ связана прежде всего с масштабами города. Можно ли рассматривать всё его население как сообщество (в этом направлении развивается, к примеру, теория местных сообществ, связывающая их с муниципальными образованиями [4, с. 117])? Некоторые исследователи городской политики, в том числе В. Г. Ледяев, также используют подобный подход [5]. На наш взгляд, он может быть продуктивен для относительно небольших населенных пунктов, но не позволяет описать процессы формирования сообществ в крупных городах. В то же время Д. В. Трофименко предлагает 
рассматривать городское сообщество как локальное полиструктурное соединение социально-территориальных общностей жителей города, где локализация социальной жизни происходит в соответствии с социально-территориальными принципами проживания людей и сопровождается автономизацией индивидов [6, с. 8]. В их структуре выделяются места создания сообществ (исторически сложившиеся районы, микрорайоны, специально организованные пространства), объединяющие территориальную привязку (локации проживания) и социальные интересы людей. Сообщностные отношения при этом задаются временной синхронизацией жизни людей [7].

Однако необходимо учитывать, что население города, как правило, имеет высокий уровень демографической сложности. Это обстоятельство, равно как и разрозненность горожан в условиях интенсивной миграции, обусловливает наличие очень слабых связей между ними и затрудняет формирование сообществ [8]. Такое состояние отношений косвенно подтверждается и слабой выраженностью субгородских идентичностей, фиксируемой российскими исследователями [9].

Согласно определению Ю. Д. Якубова, под городскими сообществами понимаются добровольные самодеятельные и автономные по отношению к органам публичной власти объединения людей, проживающих в границах города и имеющих целью удовлетворение интересов и потребностей [10, с. 4-5]. На их основе формируется социальный капитал, проявляющийся в создании социальных сетей и выступающий фактором активизации других ресурсов местного сообщества [11]. Одной из исследовательских традиций, сложившихся в области научных исследований городских сообществ, является «экологическая», связывающая образование такого сообщества с определенным местом обитания: кварталом, районом и т. д. [12]. При этом большое значение имеет проблема совпадения территориальных и социальных границ таких сообществ [13]. Вопрос о локализации городских сообществ (и сообществ вообще) усложнился с распространением новых коммуникативных технологий, на основе которых формируются и взаимодействуют online-сообщества и «сообщества online» [14]. Постепенно на первый план в качестве основания жизни сообщества, по мнению ряда исследователей, выходит не территория, но коммуникация. В связи с этим актуализируются такие параметры их описания, как структура коммуникативных обменов, событийная архитектура, коды коммуникации [15]. Не меньшую роль сыграло развитие сетевой теории, которая позволила рассматривать сообщества как структуры со «слабыми связями». В рамках концепции сетевого общества новые формулировки получает само понятие сообщества, рассматриваемого в ракурсе циркулирующих информационных потоков, вплоть до стирания различий между актором и структурой (акторно-сетевая теория Б. Латура). Здесь же возникает представление о сети как способе выявления ранее неизвестных актору компонентов целого [16].

\section{Городские сообщества в политическом пространстве города}

Какие-то из сообществ по интересам могут быть локализованы в общегородском масштабе (объединение горожан на основе хобби, общего времяпровождения и др). Также общегородской характер могут иметь сообщества активистов (как правило, представленных в сообществах локального масштаба), выходящие на уровень политико-управленческих взаимодействий с местными и региональными органами власти. Они приближаются к формату городских движений и могут приобретать политическое измерение, в том числе и в условиях конфликта [17]. 
Локализация сообществ в той или иной части городского пространства также связана с характером взаимодействия между членами сообщества. По данному критерию их обычно разделяют на соседские, гражданские и политические. Сообщества первого типа создаются в связи с проблемами общежития в конкретной городской локации (двор, жилой комплекс, отдельный городской квартал и др.). Взаимодействие в них также связано с решением насущных проблем «своего» (освоенного данным сообществом) пространства и, как правило, приобретает публичную составляющую в случае возникновения каких-либо угроз его целостности или качественному состоянию (принцип NIMBY [18], который, впрочем, приобрёл негативный контекст в своевременном общественно-политическом дискурсе). При этом некоторые исследователи оценивают NIMBY как явление, способствующее развитию муниципальной демократии и общественных движений [19]. Соседские взаимодействия также рассматриваются как один из источников локального активизма [20].

Таким образом, гражданская составляющая в деятельности соседских сообществ формируется, если им приходится сталкиваться с проблемами, для решения которых ресурсов самих сообществ недостаточно, и публично апеллировать к гражданским правам и политической власти. Усиление инициативности горожан в таких случаях может вызвать и рост протестных настроений [21, с. 344]. Однако развитие сообщества возможно и через конструктивные практики (улучшение городской среды, вовлечение жителей города в процесс формирования городского пространства) $[22 ; 23]$. Устойчивость сообества обеспечивается различными видами инноваций [24], часто возникающих через конфликт [25]. В целом гражданское сообщество ориентировано на развитие города или отдельных сфер его жизни.

Возникновение политического сообщества возможно в условиях публичного обращения к власти, оппонирования ей либо непосредственной борьбы за властные полномочия. «Самодеятельные» политические сообщества в городском пространстве являются «инфраструктурным ядром» гражданских кампаний. Предполагается, что высокий уровень их включённости (возможность оказывать влияние на городскую политику) обусловлен: а) «лояльностью» городской среды - других политических акторов; б) степенью договороспособности группы (её способность идти на компромисс в достижении выдвинутых требований, способность взаимодействовать с разными акторами) [26]. Как отмечает С. Мурунов, для участия в формировании и реализации городской политической повестки сообщества нуждаются в «городских политиках» - активистах или экспертах, которые «вербализируют ... и опубличивают общие интересы». Появление таких людей, действующих на постоянной основе, способствующих кооперации городских сообществ на основе определённых тем [27], признак их политизации. Они также могут выступать важной силой городского протеста, регулярно проводя публичные мероприятия, привлекая внимание средств массовой информации и участников, давая возможность для выдвижения своих требований представителям объединений с неполитической повесткой дня [28].

Таким образом, сообщества различного типа могут трансформироваться под влиянием внутренних или внешних факторов, в том числе конфликтов: как переходить к новому типу взаимодействия, так и редуцировать к прежнему. Кроме того, сообщества могут образовывать сетевые структуры, узлами которых являются городские активисты. Как демонстрирует на примере г. Омска российский исследователь, они могут быть задействованы одновременно в деятельности разных проектов и городских сообществ [29]. Предлагается рассматривать их также и как потоковые структуры, в духе исследования Д. В. Иванова [30]. 
Формирующиеся сетевые структуры могут включать в себя не только общественников и активистов, но и экспертов, представителей бизнеса и власти [31]. В этом аспекте сетевые сообщества могут рассматриваться как институты, обеспечивающие координацию интересов различных сегментов населения города и их участие в принятии решений на уровне местного самоуправления. Степень их участия в управлении городом зависит от уровня субъектности, который определяется сплочённостью, эмоциональной вовлечённостью, ответственностью членов сообщества и рядом других характеристик [32].

\section{Городские сообщества в условиях конфликта}

Исследователями признаётся значительная роль сообществ в создании полицентричной структуры городской политики, основанной на гражданском участии и обеспечивающей устойчивость и адаптивность городов. В то же время такая структура призвана способствовать преодолению конфликтов [33]. С этой проблемой сталкиваются все города, в которых социально-экономическое развитие приводит к росту гражданского самосознания и, как следствие, росту конфликтов, в первую очередь основанных на уже упоминавшейся идее NIMBY. Инструменты регулирования таких конфликтов делятся на три категории: рыночные инструменты, методы управления бизнесом и инструменты социального управления [34, p. 149-150].

Существует также подход, согласно которому можно выделить государственное регулирование, предполагающее использование наиболее жёстких инструментов (правовое регулирование, стандартизация, силовые методы подавления конфликтов); совместное управление, основанное на создании «мультиагентов» (сотрудничество властных структур, бизнеса и общественных структур, вовлечение граждан в принятие решений); экономическое стимулирование, ориентированное на рыночные формы урегулирования конфликтов (выплата компенсаций, снижение налогов или освобождения от их уплаты для сообществ, чьи интересы затронуты) [35]. Исследователями отмечается, что вне зависимости от конкретных механизмов регулирования повышение конструктивности в управлении подобными конфликтами желательно для всех участников, т. к. способствует развитию демократических механизмов на местном уровне и в то же время ускоряет процесс размещения необходимых городу объектов.

Исследования участия городских сообществ в конфликтах и стратегий их поведения нельзя назвать многочисленными. Необходимо отметить ряд статей Е. В. Тыкановой (некоторые из них опубликованы в соавторстве с А. М. Хохловой, А. Н. Шаталовой, А. А.Желниной), посвящённых теоретическим аспектам данной проблематики [36], анализу case-study [37; 38; 39] и некоторым смежным аспектам [40].

Проводимые в течение нескольких лет исследования деятельности городских сообществ в условиях конфликтов, имеющих, как правило, политическую составляющую, позволяют отслеживать динамику её форм и методов. В частности, отмечается, что появляются новые игроки и форматы городского локального протеста, а их динамика демонстрирует постепенную политизацию, а именно сложное, нелинейное «восхождение» гражданского участия от индивидуализированных до более коллективных, сетевых и политизированных форм [41, с. 42]. При этом само понятие городского конфликта в исследованиях санкт-петербургских авторов фигурирует достаточно редко, как правило, речь идёт об оспаривании городского пространства, согласовании интересов, городском протесте и т. д. 
Вызывают интерес исследования участия городских сообществ в конфликтах по поводу развития пригородных районов. Здесь речь идёт о проблемах землепользования, идентичности сообществ, дискурсах по поводу развития городского пространства и их практическом влиянии на городской ландшафт [42; 43; 44; 45]. Однако в них указанная тематика не является основной, и этот вопрос требует дальнейшего изучения, в том числе в связи с ростом городских агломераций.

Достаточно широко распространены подходы к городскому планированию, в которых данный процесс рассматривается с точки зрения вовлечения сообществ и преодоления конфликтов городского развития. В XXI в. отмечается рост влияния акторов, участие которых в городском планировании ранее было незначительным. Гражданские структуры и активисты начинают играть ключевую роль [46]. Одним из главных методов обеспечения такого положения вещей в пространстве города является коллаборативное (коммуникативное) планирование, определяемое в качестве «основанной на гражданственности модели планирования, которая делегирует ответственность за подготовку планов непосредственно заинтересованным сторонам» [47]. П. Хили рассматривает такой процесс планирования как переход от выработки стратегии к дискуссиям и «включающей стратегической аргументации», к развитию «политического дискурса» и реализации предложений [48]. Данные механизмы работоспособны при условии приложения необходимых усилий для их налаживания (в частности, привлечения специалистов, обладающих навыками фасилитации, работы с конфликтующими группам и др.).

Альтернативным вариантом планирования является критический подход, предполагающий борьбу за городское пространство, открытое столкновение интересов по поводу планов его использования. Данный подход сформировался в русле неомарксизма и отражает идеи, согласно которым бороться необходимо не за достижение компромисса по отдельным спорным вопросам, а за изменение структуры самого городского пространства в интересах большинства горожан. Таким образом, конфликт рассматривается как одно из проявлений базовых противоречий современного общества. Здесь возможно возникновение более глубоких конфликтов, связанных не только с интересами, но и с ценностями различных групп горожан [49]. Критическое планирование предполагает открытое политическое высказывание, имеющее публичное звучание, и мобилизацию значительного количества людей для поддержки заявленной позиции. Соответственно, разрешения конфликта можно достичь только посредством реального перераспределения властных полномочий и схем управления городским развитием [50]. Для этого варианта планирования значимой является способность горожан объединяться и отстаивать свои интересы политическими методами, в том числе и через структуры гражданского общества.

\section{Заключение}

Подводя итог представленного обзора современного состояния исследований проблематики конфликтов в процессе функционирования городских сообществ, отметим, что различные её аспекты весьма неравномерно представлены в научных публикациях. Наибольшее внимание уделяется проблемам определения сущности и роли городских сообществ как акторов процессов развития города, относительно меньшее - их месту в городской политике, ещё меньшее - участию в конфликтах и влиянию такого участия на развитие сообщества. Между тем данная тематика представляется ключевой в контексте активизации политической борьбы в современных крупных городах, роста городского активизма и его протестных составляющих. 


\section{Можно ожидать, что количество и уровень специализированных исследований по данному направлению будут возрастать.}

\section{Ссылки / References}

1. Семенов А. В., Шевцова И. К., Бедерсон В. Д. Городская мобилизация и градостроительная политика: стратегическое взаимодействие местных жителей и застройщиков в ситуации конфликта // Журнал социологии и социальной антропологии. 2018. № 21(3). C. 140-169. DOI: 10.31119/jssa.2018.21.3.7

2. Парк Р. Э. Социология, сообщество и общество // Вопросы социальной теории. 2008. Т. 2. Вып. 1(2). С. 227-231.

3. Вагин В. Социология города. М.: МОНФ, 2000.

4. Демчук Н. В. Местное сообщество: интерпретация понятия // Вестник Майкопского государственного технологического университета. 2019. № 2(41). С. 111-117.

5. Ледяев В. Г. Опыт изучения власти в городских сообществах: российская проекция // Власть и элиты. Т. 5. СПб.: Интерсоцис, 2015. С. 301-325.

6. Трофименко Д. В. Городское сообщество: разрешение институциональных конфликтов в полиэтничной среде: дис. ... канд. соц. наук. Ростов-на-Дону, 2008.

7. Степанцов П. Сообщества и городская среда. URL: https://postnauka.ru/faq/11357

8. Nguyen H., Tyler S., Thi My Thi Tong. Co-management model on urban riverbank erosion management in Can Tho city, Vietnam // Science and Technology in Disaster Risk Reduction in Asia. Potentials and Challenges. 2018. P. 161-173.

9. Городские локальные идентичности: проблемы дифференциации и факторы консолидации местных сообществ / Р. В. Евстифеев, И. В. Задорин, П. Л. Крупкин, С. Д. Лебедев // Региональная дифференциация и консолидация социального пространства России: новые реалии и вызовы. V Сухаревские чтения: материалы Всероссийской научно-практической конференции. Саранск: Научный центр социальноэкономического мониторинга, 2015. С. 368-373.

10. Якубов Ю. Д. Неполитические общественные объединения как фактор политики: дис. ... канд. полит. наук. Казань, 2003.

11. Рослякова М. В. Городские сообщества как объект и важнейший ресурс муниципального управления // Политика и Общество. 2018. № 8. C. 42-55. DOI: 10.7256/24540684.2018.8.27143.

12. McKenzie R., Park R., Burgess E. The City. Chicago: University of Chicago Press, 1967.

13. Пузанов К. А. Территориальные границы городских сообществ // Социология власти. 2013. № 3. C. 27-38.

14. Павлов А. В. Локальные городские сообщества в социальных сетях: между «соседской» и «гражданской» коммуникацией // Лабиринт. Журнал социально-гуманитарных исследований. 2016. № 5. С. 46-57.

15. Вахштайн В. Производство сообществ: событие, язык, коммуникация // 60 параллель. 2011. № 2. C. $72-81$.

16. Latour B. Network, societies, spheres: Reflections of an actor-network theorist // International journal of communication. 2011. Vol. 5. P. 796-810.

17. Городские движения России в 2009-2012 годах: на пути к политическому / под ред. К. Клеман. М.: Новое литературное обозрение, 2013. 
18. Been V., Madar J., McDonnell S. 2014. Urban Land-Use Regulation: Are Homevoters Overtaking the Growth Machine? // Journal of Empirical Legal Studies. 2014. № 11 (2). P. 227-265.

19. Léa S. From NIMBY to enlightened resistance: A framework proposal to decrypt landuse disputes based on a landfill opposition case in France // Local Environment. 2017. № 22 (4). P. 461-477.

20. Петухов Р. В. Локальные сообщества и гражданский активизм // Мониторинг общественного мнения: экономические и социальные перемены. 2014. № 4 (122). C. 60-67.

21. Ивлева И. В. Соседские сообщества в процессе трансформации // Вестник СПбГУ. Серия 12. 2010. Вып. 3. С. 339-345.

22. Оводова С. Н. Гражданские и религиозные сообщества в городе: отпечатки социального порядка в пространственной конфигурации // Визуальные образы современной культуры: светские и религиозные стратегии построения жизненного мира: сборник научных статей по материалам VI Всероссийской научно-практической конференции (Омск, 9-10 июня 2017 г.). Омск: Изд-во Ом. гос. ун-та, 2017. С. 58-59.

23. Оводова С. Н. Городские сообщества: собирая и разрушая города. Визуальные образы современной культуры // Человек в современном городе: облик, образ, образование: сб. науч. ст. по материалам V Всерос. науч.-практ. конф. с международ. участием (Омск, 17 18 мая 2016 г.). Омск: Изд-во Ом. гос. ун-та, 2016. С. 30-31.

24. Horgan D.; Dimitrijević B. Social Innovation Systems for Building Resilient Communities // Urban Sciens. 2018. № 2. P. 1-16.

25. The International Handbook on Social Innovation: Collective Action, Social Learning and Transdisciplinary Research / F. Moulaert, D. MacCallum, A. Mehmood, A. Hamdouch. Cheltenham: Edward Elgar Publishing, 2013.

26. Демакова К. В. Роль самодеятельных сообществ в городской политике // Вестник Пермского университета. Серия: Политология. 2013. № 4 (24). С. 116-126.

27. Мурунов С. Городские политики или технологии влияния городских сообществ. URL: https://arch-sochi.ru/2019/04/gorodskie-politiki/

28. Пустовойт Ю. А. «Земля» и «воля»: городские режимы и протестные сообщества в сибирских городах // Власть и элиты. 2018. Т. 5. С. 295-330.

29. Оводова С. Н. Феномен самоорганизации активистов в урбанистические сообщества (на примере г. Омска) // PRIMO ASPECTU. 2019. № 2 (38). С. 35-43.

30. Иванов Д. В. К теории потоковых структур // Социологические исследования. 2012. № 4 (336). С. 8-16.

31. Макарова М. Н. Городские сообщества как политические сети // Философия и социальные науки в современном мире: Материалы международной научной конференции к 30-летию факультета философии и социальных наук Белорусского государственного университета. Минск: БГУ, 2019. С. 416-421.

32. Разинский Г. В. Муниципальная власть и местные сообщества: пути оптимизации отношений // Вестник Пермского национального исследовательского политехнического университета. Социально-экономические науки. 2018. № 3. С. 162-173.

33. Sanchez A., van der Heijden J. \& Osmond P. The city politics of an urban age: urban resilience conceptualizations and policies // Palgrave Commun. 2018. № 4 (1). P. 1-12. DOI: 10.1057/ s41599-018-0074-z

34. Chen Z. M. Public Policy. Beijing: China Renmin University Press, 2013. 
35. Liu Y. (2018). Research on the Influence Factors of the Policy Tools in NIMBY Conflict Management - A Study Based on 25 Cases in China // Open Journal of Social Sciences. 2018. № 6. P. 164-174.

36. Желнина А. А., Тыканова Е. В. Формальные и неформальные гражданские инфраструктуры: современные исследования городского локального активизма в России // Журнал социологии и социальной антропологии. 2019. № 1. С. 63-84.

37. Тыканова Е. В. Консолидация локальных сообществ в ситуации оспаривания городского пространства Санкт-Петербурга // Петербургская социология сегодня. 2016. № 7. C. 364-388.

38. Тыканова Е. В., Хохлова А. М. Между политическим и аполитичным: формы участия локальных сообществ в защите городских территорий // Современный город: власть, управление, экономика. Пермь: ПНиПу, 2017. С. 218-236.

39. Тыканова Е. В. Город как территория неравенства: оспаривание сноса гаражных строений в Санкт-Петербурге // Петербургская социология сегодня. 2017. № 8. С. 54-72.

40. Шаталова А. Н., Тыканова Е. В. Неформальные практики участников публичных слушаний (случай Санкт-Петербурга) // Журнал социологии и социальной антропологии. 2018. № 4. С. 63-84.

41. Тыканова Е. В. Уровни участия локальных активистов в борьбе за городское пространство // Город. Среда. Политика. 2018: сборник материалов научнопрактической конференции. СПб.: РГПУ им. А. И. Герцена, 2019. С. 37-42.

42. Anderson N. M., Ford R. M., Williams K. J. H. Contested beliefs about land-use are associated with divergent representations of a rural landscape as place // Landscape and Urban Planning. 2017. № 157. P. 75-89.

43. Cadieux K. V. Political ecology of exurban "lifestyle" landscapes at Christchurch's contested urban fence // Urban Forestry Urban Greening. 2008. № 7. P. 183-194.

44. Kennedy M., Butt A., Amati M. Conflict and change in Australia's peri-urban landscapes. Farnham: Routledge, 2016.

45. Ruoso L.-E., Plant R. A politics of place framework for unravelling peri-urban conflict: An example of peri-urban Sydney, Australia // Journal of Urban Management. 2018. № 7 (2). P. 57-69.

46. Urban Politics: An Interdisciplinary Dialogue // International Journal of Urban and Regional Research. 2011. № 35(4). P. 853-871.

47. Gunton T. \& Day J. C. The theory and practice of collaborative planning in resource and environmental management // Environments. 2003. № 31. P. 5-19.

48. Healey P. Collaborative Planning: Shaping Places in Fragmented Societies. Vancouver: UBS Press, 1997.

49. McAuliffe C. \& Rogers D. The politics of value in urban development: Valuing conflict in agonistic pluralism // Planning Theory. 2019. № 18 (3). P. 300-318.

50. Медведев И. Р. Разрешение городских конфликтов. М.: Инфотропик, 2017. 